\title{
Education Needs for Nurses in Adult and Paediatric Units
}

\author{
Michelle Kenyon, John Murray, Rose Ellard, and Daphna Hutt
}

Complex nursing care for patients on the CAR-T cell therapy pathway involves many different nursing roles that have important functions at different stages in the pathway. Within the multiprofessional team, nurse education is critical to safe and competent care and to the patient's treatment experience. As we consider the education needs of the nursing workforce throughout the entire patient pathway, including the supply chain, chain of custody, and clinical care delivery, we recognize the important roles of expert nurses, practice educators, and the wider multiprofessional team in sharing their knowledge and experience. Nurse education strategies should include referring nursing teams to facilitate seamless patient care throughout referral, treatment, and follow-up to optimize communication and appropriately meet patient and caregiver information needs.

Treatment plans can change rapidly; patients do not reach the point of treatment or relapse during admission. The involvement of disciplines such as palliative care and psychological therapy in the programme is key. The relationship between the

\footnotetext{
M. Kenyon $(\bowtie)$

Department of Haematological Medicine, King's College Hospital, NHS Foundation Trust, London, UK

e-mail: michelle.kenyon@nhs.net

\section{J. Murray}

Haematology and Transplant Unit, The Christie NHS Foundation Trust, Manchester, UK e-mail: j.murray10@nhs.net

R. Ellard

The Royal Marsden NHS Foundation Trust, London, UK

e-mail: rose.ellard@nhs.ne

D. Hutt

Department of Pediatric Hematology-Oncology and BMT, Edmond and Lily Safra Children's Hospital, Sheba Medical Center, Ramat Gan, Israel

e-mail: dhutt@sheba.health.gov.il
} 
referring and treating centre is critical, and an active dialogue between teams from the time of referral is imperative to optimize patient care.

\section{Apheresis and Cell Collection}

Nurses with the knowledge, skills, and expertise to perform CAR-T-specific apheresis procedures do so in many JACIE accredited centres following training and competency achievement. Apheresis booking is synchronized with the availability of manufacturing space in the pharmaceutical company, but timing is critical to maximize collection quality and minimize the risk of unsalvageable disease progression. Preprocedure work-up can include disease- and product-specific tests and screening. Technically, apheresis is similar to donor lymphocyte or mononuclear cell procedures but may be more challenging due to low lymphocyte counts following earlier treatments. The patients may be symptomatic due to the disease burden and previous therapies and can become unwell during harvest.

\section{Cell Infusion}

Thawing and cell infusion are performed in most centres by appropriately trained nurses. Frozen cells are shipped from the manufacturer, and thawing occurs at the bedside via a water bath or automated device. Specific training on defrosting and infusing the product is mandatory. Soft waste will be disposed of into a double clinical waste bag, tagged, numbered, and placed in a dedicated biohazard waste container. Sharp waste, e.g., syringes and vials, must be placed in sealed and lidded sharps container, which is tagged and labelled as biohazard waste. A disposal record should be maintained. PPE should be worn at all times of disposal. If clothing becomes contaminated, it should be changed immediately and disposed of as soft waste. If spillage occurs, the spill should be cleaned while wearing PPE and using Clinell red wipes or other virucidal products. Routine checks are performed at the bedside (patient ID, consent, prescription, vital signs, IV access). Premedication is administered, ensuring that no steroids are given. The cells are infused as per local policy and the product specification. The patient's vital signs are recorded during and following the infusion. All necessary documentation is completed. The infusion is usually uneventful, but intensive care and neurology services should be notified of the CAR-T infusion should their support be needed during the postinfusion period.

\section{Patient Monitoring}

The two most common toxicities following CAR-T infusion are cytokine release syndrome (CRS) and immune effector cell-associated neurotoxicity syndrome (ICANS). 
CRS is the most common acute toxicity. Frequently reported symptoms are fever, hypoxia, and hypotension, which can mimic neutropenic sepsis. Thus, the patient must be treated for suspected infection with intravenous antibiotics and a full septic screen must be performed.

ICANS symptoms can be progressive and may include aphasia, an altered level of consciousness, impairment of cognitive skills, motor weakness, seizures, and cerebral oedema (Lee et al., 2019). Nurses should be aware of these symptoms, and familiarity with the patient's baseline condition aids in monitoring for subtle changes.

Vital signs of inpatients should be recorded at least once every $4 \mathrm{~h}$ to monitor for signs/symptoms of CRS. Patients may deteriorate quickly, and nurses should promptly report concerns to the medical team to ensure early recognition and treatment. The recommended monitoring and assessment tools for CRS and ICANS are the American Society of Transplant and Cellular Therapy CRS consensus grading (Table 1 in Chap. 26), immune effector cell-associated encephalopathy (ICE) tool (Table 1 in Chap. 27), and the ASTCT ICANS consensus grading (Table 2 in Chap. 27) (Lee et al., 2019). The CRS grade should be calculated if there is a deterioration in the patient's vital signs and reported to the medical team. The ICE score should be calculated at least twice daily. This tool is of particular benefit, as subtle handwriting changes can be an early sign of ICANS. If the ICE score is less than 10, the ASTCT ICANS grade (Table 3 in Chap. 27) should be calculated and the medical team notified of the change in the patient's condition. Patients require daily blood tests, including full blood count, biochemistry, CRP, and ferritin; some centres may have additional routine tests.

\section{Toxicity Management}

Treatment of symptoms is a key nursing role in the management of CAR-T toxicities. Patients with suspected CRS may require supportive measures, such as paracetamol, IV fluids, or supplemental oxygen. The first-line medicinal treatment for CRS is tocilizumab, an anti-IL6 monoclonal antibody given intravenously. Up to four doses can be given, at least $8 \mathrm{~h}$ apart. Second-line treatment for CRS is usually corticosteroids, although these are always used with caution due to the potential deleterious effect on CAR-T cell efficacy. However, ICANS is typically treated with corticosteroids as a first line because tocilizumab is a large molecule and does not cross the blood-brain barrier.

\section{Discharge}

Upon discharge, patients and their caregivers should have written information about potential side effects and who and how to contact an appropriate CAR-T member if they develop problems or concerns. Patients must be aware of the symptoms of CRS and serious neurological reactions and the need to report all symptoms to the CAR-T 
team immediately. If discharged prior to day 28 , patients are required to remain within close proximity of the treatment centre until day 28. They are also advised not to drive for 8 weeks post-infusion or resolution of neurologic symptoms due to the risk of delayed neurotoxicity. Ideally, they should have a responsible adult as a caregiver for the first 3 months at home.

\section{Long-Term Follow Up}

In the CAR-T setting, the recommended minimum duration of follow-up is 15 years, with annual assessment, which fulfils the regulatory requirements and allows submission of longitudinal outcome data that can contribute to the growing evidence base. The range of assessments and late effects screening can vary between products and disease indications. Nurse awareness is necessary to support the patient with appointments, coordination of tests, communication of results, and escalation of patient concerns when raised. Early quality of life data show promising improvements (Tam et al. 2019) for some patients who achieve PR and CR. Survivorship care, supporting the patient and caregiver through the transition from treatment through recovery and beyond, is a key area for nurse development.

\section{Paediatric Considerations}

Currently, tisagenlecleucel (Kymriah ${ }^{\mathrm{TM}}$ ) is the only approved treatment for refractory/relapsed ALL in children and young adults up to 25 years of age. Apheresis in small children is considered safe but challenging because it has potentially more side effects than in adults due to the small body mass and unique physiology of children. Venous access in small children can be difficult and limits inlet rates and in some cases requires insertion of a leukapheresis catheter (Mahadeo et al. 2019). Children weighing 20-25 kg may require priming of the machine with packed red cells prior to the apheresis procedure. Metabolic complications due to citrate toxicity may present differently in children (Del Fante et al. 2018). Obtaining a sufficient number of harvested cells could be a limiting factor in infants and small children (Hayden et al. 2021). In the pre-apheresis consultation, the nurse should consider all of the above issues and provide age-appropriate preparation for the procedure, including descriptions of the sequence of events that will occur and accurate information on what pain and sensations to expect.

Hypotension and hypoxia are the principal determinants of the consensus grading scale, and hypotension assessment should account for age and the patient's individual baseline. Although the 10-point ICE assessment is useful for screening adults for encephalopathy, its use in children may be limited to those aged $\geq 12$ years with sufficient cognitive ability to perform it. In children aged $<12$ years, the Cornell Assessment of Pediatric Delirium (CAPD) is recommended to aid in the overall grading of ICANS (Lee et al. 2019) (Table 40.1). 
Table 40.1 Encephalopathy assessment for children age $<12$ years using the CAPD

Answer the following based on interactions with the child over the course of the shift

\begin{tabular}{l|l|l|l|l|l}
\hline & Never, 4 & Rarely, 3 & Sometimes, 2 & Often, 1 & Always, 0 \\
\hline $\begin{array}{l}\text { 1. Does the child make eye } \\
\text { contact with the caregiver? }\end{array}$ & & & & & \\
\hline $\begin{array}{l}\text { 2. Are the child's actions } \\
\text { purposeful? }\end{array}$ & & & & & \\
\hline $\begin{array}{l}\text { 3. Is the child aware of his or } \\
\text { her surroundings? }\end{array}$ & & & & & \\
\hline $\begin{array}{l}\text { 4. Does the child communicate } \\
\text { needs and wants? }\end{array}$ & & & & & \\
\hline & Never, 0 & Rarely, 1 & Sometimes, 2 & Often, 3 & Always, 4 \\
\hline $\begin{array}{l}\text { 5. Is the child restless? } \\
\text { 6. Is the child inconsolable? }\end{array}$ & & & & & \\
\hline $\begin{array}{l}\text { 7. Is the child underactive; very } \\
\text { little movement while awake? }\end{array}$ & & & & & \\
\hline $\begin{array}{l}\text { 8. Does it take the child a long } \\
\text { time to respond to } \\
\text { interactions? }\end{array}$ & & & & & \\
\hline
\end{tabular}

Adapted from Traube et al. 2021; reproduced with permission

After treatment, children with B-cell aplasia should receive immunoglobulin replacement to maintain IgG levels according to institutional guidelines for IgG substitution (i.e., $\geq 500 \mathrm{mg} / \mathrm{dL}$ ) (Hayden et al. 2021).

For patients aged 1-2 years, the following serve as guidelines for the corresponding questions:

1. Holds gaze, prefers primary parent, looks at speaker.

2. Reaches and manipulates objects, tries to change position, if mobile may try to get up.

3. Prefers primary parent, upset when separated from preferred caregivers. Comforted by familiar objects (i.e., blanket or stuffed animal).

4. Uses single words or signs.

5. No sustained calm state.

6. Not soothed by usual comforting actions, e.g., singing, holding, talking, and reading.

7. Little if any play, efforts to sit up, pull up, and if mobile crawl or walk around.

8. Not following simple directions. If verbal, not engaging in simple dialogue with words or jargon. 


\section{Key Points}

- Nurse education strategies should recognize the importance of the range of nursing roles at various stages in the CAR-T patient pathway and their differing education and training needs.

- Treatment plans may not always proceed as expected, and patients can experience sudden and significant changes.

- Apheresis is technically similar to donor lymphocyte or mononuclear cell procedures but may be more challenging due to low lymphocyte counts, poor physical condition or high symptom burden.

- Specific training on defrosting and infusing the product is mandatory.

- The two most common toxicities following CAR-T infusion are cytokine release syndrome (CRS) and immune effector cell-associated neurotoxicity syndrome (ICANS), for which patients are very closely monitored.

- Nurses must be trained in the use of the CRS and ICANS assessment tools, local escalation protocols, and treatment strategies.

- Specific considerations exist for paediatric patients, and these nurses must be trained accordingly.

\section{References}

Del Fante C, Seghatchian J, Perotti C. Reflections on methodical approaches to hematopoietic stem cell collection in children. Transfus Apher Sci. 2018;57(3):425-7. https://doi.org/10.1016/j. transci.2018.05.005.

Hayden PJ, Roddie C, Bader P, Basak GW, Bonig H, Bonini C, et al. Management of adults and children receiving CAR T-cell therapy: 2021 best practice recommendations of the European Society for Blood and Marrow Transplantation (EBMT) and the Joint Accreditation Committee of ISCT and EBMT (JACIE) and the European Haematology Association (EHA). Ann Oncol. 2021;S0923-7534(21):04876-6. https://doi.org/10.1016/j.annonc.2021.12.003. Online ahead of print.

Lee DW, Santomasso BD, Locke FL, Ghobadi A, Turtle CJ, Brudno JN, et al. ASTCT consensus grading for cytokine release syndrome and neurologic toxicity associated with immune effector cells. Biol Blood Marrow Transplant. 2019;25(4):625-38. https://doi.org/10.1016/j. bbmt.2018.12.758.

Mahadeo KM, Khazal SJ, Abdel-Azim H, Fitzgerald JC, Taraseviciute A, Bollard CM, et al. Management guidelines for paediatric patients receiving chimeric antigen receptor $\mathrm{T}$ cell therapy. Nat Rev Clin Oncol. 2019;16(1):45-63.

Schmidts A, Wehrli M, Maus MV. Toward better understanding and management of CAR-T cellassociated toxicity. Annu Rev Med. 2021;72:365-82.

Tam C, Waller E, Jaeger U, Pacaud L, Ma Q, Maziarz R. Prolonged improvement in patient reported quality of life (QoL) following tisagenlecleucel infusion in adult patients (pts) with relapsed/refractory (r/r) diffuse large B-cell lymphoma (DLBCL): 19-month follow-up (FU) of the Juliet study. BBMT. 2019;25(3):181-2.

Traube C, Gerber LM, Mauer EA, Small K, Broglie L, Chopra YR, et al. Delirium in children undergoing hematopoietic cell transplantation: a multi-institutional point prevalence study. Front Oncol. 2021;11:627726. 
Open Access This chapter is licensed under the terms of the Creative Commons Attribution 4.0 International License (http://creativecommons.org/licenses/by/4.0/), which permits use, sharing, adaptation, distribution and reproduction in any medium or format, as long as you give appropriate credit to the original author(s) and the source, provide a link to the Creative Commons license and indicate if changes were made.

The images or other third party material in this chapter are included in the chapter's Creative Commons license, unless indicated otherwise in a credit line to the material. If material is not included in the chapter's Creative Commons license and your intended use is not permitted by statutory regulation or exceeds the permitted use, you will need to obtain permission directly from the copyright holder. 